\title{
Separating Physiologically and Directionally Induced Changes in PRI
}

\section{Using BRDF Models}

Thomas Hilker ${ }^{1^{*}}$, Nicholas C. Coops ${ }^{1}$, Forrest G. Hall ${ }^{2}$, T. Andrew Black3, Michael A.

Wulder $^{4}$, Zoran Nesic ${ }^{3}$, Praveena Krishnan ${ }^{3}$

1-Faculty of Forest Resources Management, University of British Columbia, 2424 Main Mall, Vancouver, BC, V6T 1Z4, Canada.

2-Joint Center for Earth Systems Technology, University of Maryland, Baltimore County Goddard Space Flight Center, Greenbelt Maryland, 20771, USA, Code 614.4

3-Faculty of Land and Food Systems,

University of British Columbia, 2357 Main Mall, Vancouver, BC, V6T 1Z4, Canada

4- Canadian Forest Service (Pacific Forestry Centre), Natural Resources Canada, 506 West Burnside Road, Victoria, BC, V8Z 1M5, Canada

* corresponding author:

Thomas Hilker

Phone: +1 (604) 827 4429, Fax :+1 (604) 822 9106, thomas.hilker@ubc.ca

\section{Pre-print of published version.}

Reference:

Hilker, T., Coops, N.C., Hall, F.G., Black, T.A., Wulder, M.A., Nesic, Z., Krishnan, P. 2008. Separating physiologically and directionally induced changes in PRI using BRDF models. Remote Sensing of Environment. 112: $2777-2788$

DOI:

doi:10.1016/j.rse.2008.01.001

\section{Disclaimer:}

The PDF document is a copy of the final version of this manuscript that was subsequently accepted by the journal for publication. The paper has been through peer review, but it has not been subject to any additional copy-editing or journal specific formatting (so will look different from the final version of record, which may be accessed following the DOI above depending on your access situation). 


\section{Introduction}

Plant physiological processes, governing biosphere-atmosphere interactions, are highly dynamic and can vary significantly over space and time as plants respond to rapidly changing environmental conditions. As a result, study of such processes requires careful consideration of the spatial and temporal dynamics involved (Hall et al., 1995). A prominent example of such a process is the photosynthetic light use efficiency $(\varepsilon)$, which describes the efficiency with which a plant can convert absorbed solar radiation energy into biomass (Monteith, 1972, 1977) thereby driving (amongst other factors) the amount of carbon accumulation in terrestrial ecosystems (Monteith et al., 1977, Field, 1991, Goetz et al., 1999). Determined by any of a large number of environmental stresses restraining the photochemical reaction process, such as nutrition supply, water, and temperature, $\varepsilon$ depends on vegetation types and varies greatly over space and time (Field and Mooney 1986, Prince and Goward 1995, Turner et al. 2003). Whilst recent years have seen considerable progress detecting $\varepsilon$ using high spectral resolution remote sensing instrumentation at the leaf, canopy, and stand scales, the angular, spatial, spectral and temporal requirements for up-scaling such observations to landscape and global levels using satellite remote sensing remain less well understood (Hall et al., 1995, Xiao et al., 2004).

One way to investigate scaling requirements for modeling ecosystem processes from satellite-derived land surface parameters is to study relationships between canopy reflectance and plant physiological processes at the stand level, using permanently established tower based remote sensing devices, allowing continuous observation of 
the canopy surface with high spatial and spectral resolution observations (Leuning et al., 2006, Hilker et al., 2007). Knowledge obtained from such studies may then be used to develop models for upscaling reflectance parameters to landscape and global scales.

Investigation of plant physiological processes at the stand level requires consideration of multiple viewing geometries, as 1) temporal dynamics require study of diurnal as well as seasonal patterns, and 2) full assessment of stand level photosynthesis from spectral reflectance requires careful observation of leaves, branches, structures, gaps, and understorey to understand how reflectance depends on viewing and illumination geometry (Asner, 1998). This information, however, is not easily obtained from nadir measurements alone (Strahler and Jupp 1990, Chen and Leblanc 1997, Goel and Grier, 1988). For instance, canopy radiance from nadir measurements originates mostly from sunlit leaves only, as radiative signals from shaded leaves are relatively weak, even though shaded leaves contribute a significant part to a plant's overall photosynthesis (Hall et al. 1992). Multi-angular observations provide a means to characterize the anisotropy of surface reflectance (Chen et al., 2005), which has been shown to contain information on the structure of vegetated surfaces and shaded parts of the canopy (Chen et al., 2003, Myneni et al., 2002, Gao et al. 2003). These multi-angular observations, however, are subject to directional reflectance effects that can confound the desired signal used for extraction of canopy information (Los et al., 2005). These effects can be described in terms of geometric and volumetric scattering effects (Jupp, 1998). The volumetric effect, driven by the canopy structure, including leaf angle distribution and total leaf area, leads to changes in path length and extinction, while the geometric effect relates to individual canopy shapes (Roujean et al., 1992, Jupp, 1998) 
causing scenes to appear darker or brighter depending on the amount of shadow cast as seen by an observer (Privette et al., 1994, Lucht et al., 2000).

One possible way to model these directional reflectance effects is using a bi-directional reflectance distribution function (BRDF), which describes how land surface reflectance varies with view zenith, solar zenith and azimuth angle (Barnsley et al., 1997, Gao et al., 2003, Los et al., 2005). Several different approaches exist to modeling BRDF, of which the semi-empirical kernel representation is the most common (Roujean et al., 1992 Wanner et al., 1995). Kernel based BRDF models represent angular reflectance distribution as linear superposition of a set of basic BRDF shapes based on relative sun position and simple measures of the canopy structure (Wanner et al., 1995). Their simple character allows acquisition of model parameters from mathematical inversion of relatively few reflectance observations, thereby facilitating applications over a wide range of spatial scales. An underlying assumption for these observations, however, is that the physiological status of the observed canopy is constant, which does not hold for narrow waveband reflectance, used to track short term changes in physiological vegetation properties. As a result, modeling BRDF is problematic (Los et al., 2005), as the observed reflectance measurements are an integrated function of both changes in geometrically induced illumination conditions and physiologically induced changes in leaf spectral reflectance.

In this paper, we develop and apply an approach to separate directional and physiologically induced reflectance effects from canopy spectra estimates by stratifying observations according to environmental conditions, which, assuming that physiology follows environmental factors, should also stratify the dataset according to physiological 
states (Los et al., 2005). Once developed, the approach is applied using tower based spectral reflectance observations of a Douglas fir (Pseudotsuga menziesii var menziesii (Mirb.) Franco) dominated forest stand in British Columbia, Canada. Within each stratified set of observations, variations in canopy reflectance status are observed using reflectance obtained from a platform mounted multi-angular spectro-radiometer over a full year with physiologically induced reflectance changes separated from directional effects using a kernel driven BRDF model.

\section{Methods}

\subsection{Research area}

The study area is a Canadian Carbon Program flux tower site, located between Courtenay and Campbell River on Vancouver Island, British Columbia, Canada $\left(49^{\circ} 52^{\prime} 7.8^{\prime \prime} \mathrm{N}, 125^{\circ} 20^{\prime} 6.3^{\prime \prime} \mathrm{W}\right)$ at $350 \mathrm{~m}$ above sea level. The coniferous forest consists of $80 \%$ Douglas fir, $17 \%$ western red cedar (Thuja plicata Donn ex D. Don) and $3 \%$ western hemlock (Tsuga heterophylla (Raf.) Sarg.) (Morgenstern et al., 2004) and is considered second-growth planted in 1949, after harvesting of the original stand (Goodwin, 1937). The understorey consists mainly of salal (Gaultheria shallon Pursh.), Oregon grape (Berberis nervosa Pursh), vanilla-leaf deer foot (Achlys triphylla (Smith) DC), various ferns and mosses (Morgenstern et al., 2004). A 1998 site survey found

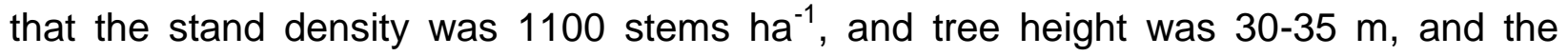
average diameter at breast height $(\mathrm{DBH})$ was $29 \mathrm{~cm}$. Chen et al. (2006) found that the 
leaf area index (LAI) was $7.3 \mathrm{~m}^{2} \mathrm{~m}^{-2}$ based on measurements using TRAC and LAI2000.

The site is among the most productive in Canada, with harvest rotation cycles as short as 60 years (Morgenstern et al., 2004). The soil is a humo-ferric podzol with a gravelly sandy loam texture and a surface organic layer ranging from 1 to $10 \mathrm{~cm}$ in depth. The total soil $\mathrm{C}$ content to $1 \mathrm{~m}$ is $11.5 \mathrm{~kg} \mathrm{Cm}^{-2}$, of which $2.5 \mathrm{~kg} \mathrm{Cm}^{-2}$ is in the surface organic layer (Drewitt et al., 2002, Morgenstern et al., 2004). The research area is part of the dry maritime Coastal Western Hemlock biogeoclimatic subzone (CWHxm) with an average annual precipitation of $1500 \mathrm{~mm}$ and mean annual temperature of $8.5^{\circ} \mathrm{C}$ (Humphreys et al., 2006). This subzone is characterized by a maritime climate with typically cool summers and mild winters, but can experience significant drought conditions during late summer and early autumn. Year-round eddy covariance flux measurements have been made since 1997 and the site (referred to as DF49) was part of the Fluxnet-Canada Research Network from 2002 to 2007 (Morgenstern et al., 2004, Margolis et al., 2006).

\subsection{Eddy covariance data}

Continuous, half-hourly fluxes of $\mathrm{CO}_{2}$ and water vapor were measured above the canopy between April $1^{\text {st }} 2006$ and March $31^{\text {st }} 2007$ using the eddy covariance (EC) technique (Morgenstern et al., 2004, Humphreys et al., 2006). EC fluxes were measured with a three-axis sonic anemometer-thermometer (SAT, R3, Gill Instruments Ltd., Lymington, UK) and a closed-path $\mathrm{CO}_{2} / \mathrm{H}_{2} \mathrm{O}$ infrared gas analyzer (IRGA) (LI-6262, LI-COR Inc., Lincoln, NE, USA). Net ecosystem exchange (NEE) was calculated as the 
sum of the half-hourly fluxes of $\mathrm{CO}_{2}$ and the rate of change in $\mathrm{CO}_{2}$ storage in the air column between the ground and the EC measurement level $(42 \mathrm{~m})$. Incident and reflected photosynthetically active radiation (PAR $\left.\left[\mu \mathrm{mol} \mathrm{m}^{-2} \mathrm{~s}^{-1}\right]\right)$, defined as the photon flux between 400-700 nm wavelength, were measured using up and downward looking quantum sensors (model $190 \mathrm{SZ}$, LI-COR Inc.), installed above and below the canopy and diffuse PAR was measured using a "sunshine sensor" (model BF3, Delta-T Devices Ltd., Burwell, UK). Wind speed related gaps in $\mathrm{CO}_{2}$ fluxes of less than $2 \mathrm{~h}$ were filled using linear interpolation. Half-hourly measurements of gross primary production (GPP) were calculated using,

$$
G P P=N E P+R_{d}
$$

where NEP is the daytime net ecosystem production (NEP=-NEE) and $R_{d}$ is the daytime ecosystem respiration (Morgenstern et al., 2004), calculated using the annual exponential relationship between nighttime NEE and soil temperature at 5-cm depth after applying a logarithmic transformation to correct for heteroscedasticity (Black et al., 1996, Goulden et al., 1997). Gaps in GPP were filled using a Michaelis-Menten GPP versus PAR relationship fitted to daytime data when air temperature $T_{\text {Air }}>-1{ }^{\circ} \mathrm{C}$ (see Morgenstern et al., 2004, Jassal et al., 2007). Half hourly $\varepsilon$ was calculated from GPP using the light use efficiency term of Monteith $(1972,1977)$ :

$$
\varepsilon=\frac{G P P}{P A R \times f_{P A R}}
$$

where $P A R$ is the half-hour PAR incident upon the canopy and $f_{P A R}$ represents the halfhour fraction of PAR being absorbed by the plant canopy. $f_{P A R}$ was determined from the ratio of incident to reflected total PAR measured above and below the canopy $\left(\rho_{1}(\theta)\right.$ and 
$\left.\rho_{2}(\theta)\right)$, respectively, the solar zenith angle $(\theta)$ at the time of measurement and the effective leaf area to account for clumping effects $\left(\mathrm{LAl}_{\mathrm{e}}\left[\mathrm{m}^{2} \mathrm{~m}^{-2}\right]\right)($ Chen 1996):

$$
f_{P A R}=\left(-\rho_{1} \boldsymbol{\theta}-\left(-\rho_{2} \boldsymbol{\theta}\right)^{\mathbf{G}_{t} \boldsymbol{\theta}\left(A I_{e} / \cos \theta_{-}\right.}\right.
$$

where $G_{t}(\theta)$ is the projection coefficient for total PAR transmission approximated being a constant of 0.5 (Chen, 1996, Chen et al., 2006) and $\mathrm{LAl}_{\mathrm{e}}$ was defined for the mature evergreen forest as a constant 4.3 throughout the study period (Chen et al., 2006). A complete description of the EC-data and processing methods applied can be found in Morgenstern et al. (2004), Humphreys et al. (2006), and Jassal et al. (2007).

\subsection{Remotely sensed data}

Canopy reflectance measurements were obtained from an automated multi-angular spectro-radiometer platform (named AMSPEC) installed at a height of $45 \mathrm{~m}(\approx 10 \mathrm{~m}$ above the tree canopy) on the open-lattice $50-\mathrm{cm}$ triangular flux-tower (Hilker et al. 2007). The instrument features a motor-driven probe that allows observations in a $330^{\circ}$ view area around the tower. The probe rotates in $11.5^{\circ}$ intervals every 30 seconds, thereby completing a full rotation every 15 minutes. A potentiometer attached to the shaft of the motor facilitates exact measurement of the probe's position. At the end of each sweep, the sensor is returned to its original position. The spectro-radiometer used is a Unispec-DC (PP Systems, Amesbury, MA, USA) featuring 256 contiguous bands with a nominal band spacing of $3 \mathrm{~nm}$ and a nominal range of operation between 350 and $1200 \mathrm{~nm}$. To allow sampling under varying sky conditions, canopy reflectance is obtained from simultaneous measurements of solar irradiance and radiance, sampled 
every 5 seconds from sunrise to sunset. The upward pointing probe is equipped with a cosine receptor (PP-Systems) to correct sky irradiance measurements for varying solar altitudes. The downward looking probe measures canopy reflectance at a zenith angle of $62^{\circ}$ to account for canopy clumping (Chen and Black, 1991). The probe's instantaneous field of view (IFOV) is $20^{\circ}$. The outer diameter of the instrument's footprint is approximately $62 \mathrm{~m}$ at canopy height, while the elliptic instantaneous view area of the probe has a major axis of about $17.9 \mathrm{~m}$ and a minor axis of around $3.5 \mathrm{~m}$ (Figure 1). No observations were made between an azimuth of $220^{\circ}$ and $250^{\circ}$ (defined from geodetic north) due to obstruction by the tower. Reflectance measurements used for this analysis were collected continuously between April $1^{\text {st }} 2006$ and March $31^{\text {st }}$ 2007. A complete technical description of the instrument its setup and calibration can be found in Hilker et al. (2007). 


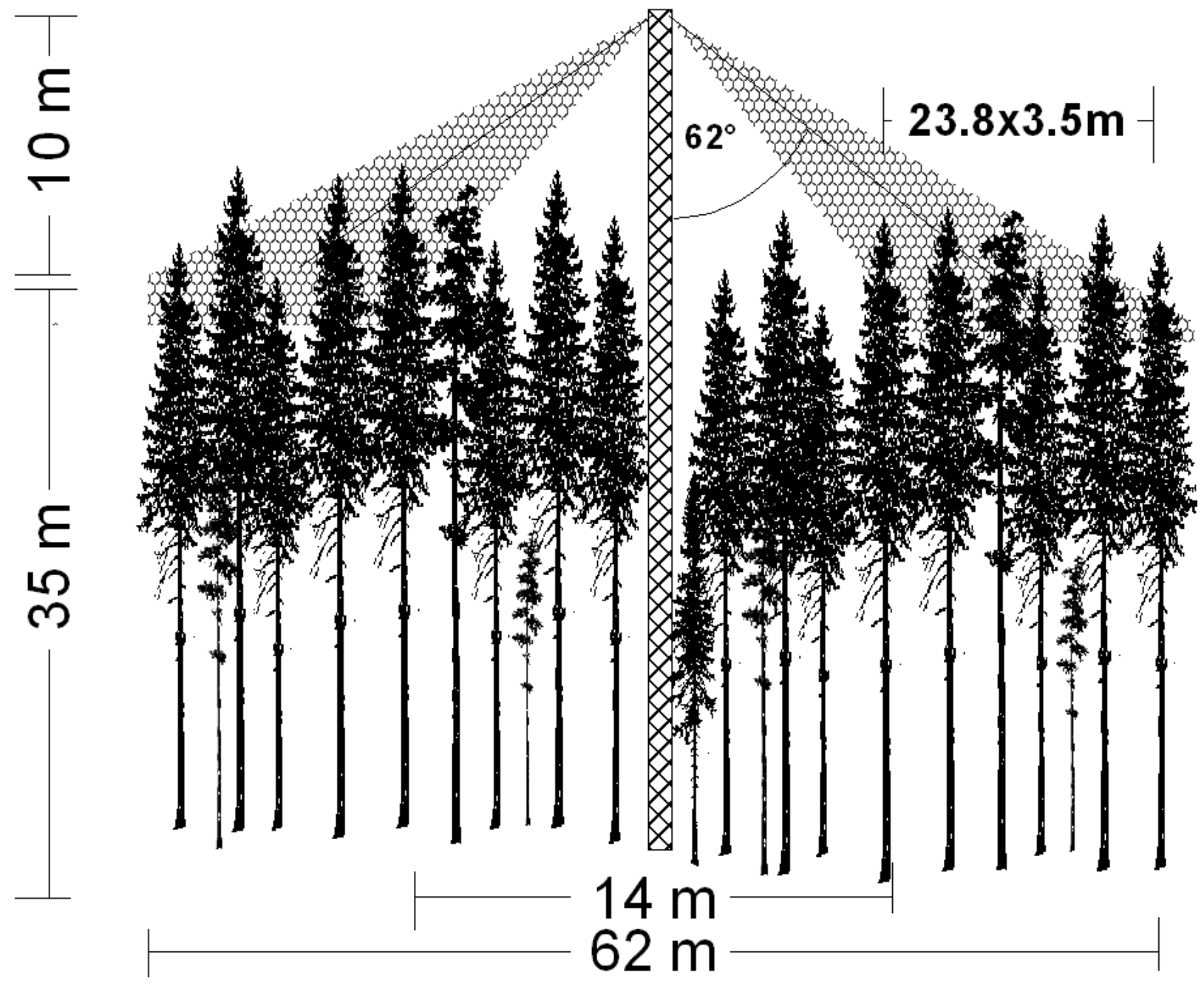

Figure 1: Area of observation of tower based spectro-radiometer and technical setup (Hilker et al., 2007). The footprint area varies slightly with individual tree height and differences in terrain height. The vertical zenith angle is $62^{\circ}$, the approximate footprint size is $62 \mathrm{~m}$ (diameter).

The sampling area for the eddy covariance measurements or "flux-footprint" depends on windspeed and atmospheric conditions (Leclerc and Thurtell, 1990), and can range from a few hectares to a few square-kilometres (Schmid and Lloyd, 1999). However, the area to which flux measurements are most sensitive, also referred to as peak footprint, is much smaller and covers a radius of only 100-300 m (Blanken et al., 2001, Kljun et al., 2004). Using the radiometer platform, about $10-20 \%$ of this area can be sampled, which can be assumed to be representative of the entire footprint, due to stand homogeneity 
of this flux tower site and as a result, spectral measurements obtained from AMSPEC are directly comparable to EC flux data (Hilker et al., 2007).

\subsection{Inferring $\varepsilon$ from remote sensing}

One way to infer \& from remotely sensed observations is narrow waveband detection of the epoxidation state of a group of leaf-pigments named xanthophylls, responsible for balancing absorption and utilization of light quanta in order to prevent oxidative damage to the photosynthetic apparatus in leaves (Demmig-Adams and Adams, 1996, DemmigAdams and Adams, 2000). Under excessive radiation conditions the xanthophyll cycle pigment violaxanthin is de-epoxidized rapidly via intermediate antheraxanthin to zeaxanthin, both of which dissipate radiation energy safely as heat, with the reaction reversed when light is limiting (Demmig-Adams and Adams, 1998). These pigment changes manifest in a narrow waveband (difference) absorption feature centered at 531 nm (Gamon et al., 1993) and hence can be quantified on leaves, canopies and stands as the Photochemical Reflectance Index (PRI), (Gamon et al., 1992, 1993, Peñuelas et al., 1995),

$$
P R I=\frac{\rho_{531}-\rho_{570}}{\rho_{531}+\rho_{570}}
$$

comparing the reflectance at $531 \mathrm{~nm}\left(\rho_{531}\right)$ to a xanthophyll-insensitive reference band at $570 \mathrm{~nm}\left(\rho_{570}\right)$. Originally established for sunflower leaves, the empirical relationship between PRI and $\varepsilon$ has been confirmed over a wide range of species (Peñuelas et al., 1994, 1995, Filella et al., 1997, Gamon and Surfus, 1999). Generalization of this 
correlation for application at the stand level and beyond, however, remains difficult (Barton and North, 2001, Rahman et al. 2001, 2004) as PRI is highly sensitive to viewangle, soil background reflectance, leaf angle distribution (at larger view angles) and leaf area (Barton and North, 2001).

For this study, high temporal frequency observations of PRI were calculated from AMSPEC-data using linear interpolation of the closest wavebands available for $530 \mathrm{~nm}$ $(529.4 \mathrm{~nm}$ and $532.7 \mathrm{~nm})$ and $570 \mathrm{~nm}(568.8 \mathrm{~nm}$ and $572.1 \mathrm{~nm})$, respectively for all solar altitudes $>10^{\circ}$ (as derived from the time of measurement, Reda and Andreas, 2004) between April $1^{\text {st }} 2006$ and March $31^{\text {st }}, 2007$.

\subsection{Modeling the bidirectional reflectance distribution of PRI}

\subsubsection{BRDF notation}

Semi-empirical kernel driven models for the BRDF of vegetated land surfaces typically consist of a linear combination of three kernels describing isotropic, geometric and volumetric scattering effects (Roujean et al., 1992). Isotropic scattering refers to the reflectance properties of an isotropic, Lambertian surface, and, assuming random leaf distribution, can be seen as aggregate property of the sum of leaves, while geometric scattering describes scattering effects due to crown shape (Roujean et al., 1992). Volumetric scattering models dispersion effects due to vertical and horizontal distribution of vegetation elements inside the tree canopy. A series of different mathematical kernels can be selected to optimize BRDF models for various kinds of vegetation cover. Among the most commonly applied functions are Ross and Li Kernels 
(Wanner et al., 1995, Lucht et al., 2000, Strugnell and Lucht, 2001) with the Ross kernels (Roujean et al. 1992) based on the radiative transfer theory of Ross (1981), whereas the Li kernels are geometric-optically based (Li and Strahler, 1986). Both types of kernels are examples of physical reflectance models. In temperate climatic zones and when observing discontinuous, stacked canopies (e.g. conifer stands), the bidirectional reflectance distribution is most commonly represented by the so called the Li-sparse (LS) and Ross-thick (RT) kernels, yielding the LSRT BRDF model as (Lucht et al., 2000, Los et al., 2005),

$$
\rho\left(\theta_{v}, \theta_{s}, \Delta \phi\right)=k_{i}+k_{g} K_{L}\left(\theta_{v}, \theta_{s}, \Delta \phi, \frac{h}{b}, \frac{b}{r}\right)+k_{v} K_{R}\left(\theta_{v}, \theta_{s}, \Delta \phi\right)
$$

where

$k_{i} \quad$ isotropic scattering component

$k_{g} \quad$ geometric scattering component

$K_{L} \quad$ Li-Sparse kernel

$k_{v} \quad$ volumetric scattering component

$K_{R} \quad$ Ross-Thick kernel

$\theta_{v} \quad$ view zenith angle

$\theta_{s} \quad$ solar zenith angle

$\Delta \phi \quad$ azimuth angle

$\frac{h}{b} \quad$ crown relative height $=1$ (Wanner et al., 1995, Justice et al, 1998)

$\frac{b}{r} \quad$ crown relative shape $=2$ (Wanner et al., 1995, Justice et al, 1998)

$k_{i}, k_{g}$ and $k_{v}$ are the empirical components (kernel weights) derived from mathematical inversion of the linear model using multi-angular radiation observations. For a surface 
that behaves in a more Lambertian manner (e.g. a smooth non-layered surface), the magnitude of the isotropic kernel coefficient $k_{i}$ of equation (5) should be larger than $\mathrm{k}_{\mathrm{g}}$ and $k_{v}$. For a continuous layered canopy, $k_{i}$ and $k_{v}$ should dominate since the RT function will better describe the directional observations. For a discontinuous coniferous canopy the LS function will better match the observations hence, $\mathrm{k}_{\mathrm{g}}$ is expected to be the larger component. The LSRT model as shown in (5) has been applied to global satellite reflectance observations for a range of vegetation canopy structures thereby permitting a semi-empirical reconstruction of the full canopy BRDF from satellite acquisitions for a limited number of view and illumination angles (Wanner et al., 1995).

When utilizing a normalized difference reflectance index (NDRI) such as the PRI that utilizes reflectance in two spectral wavelengths, the BRDF of the NDRI can either be computed for each wavelength separately or by applying a mathematical inversion to the observed index directly. The latter approach has the advantage that the residual errors are directly minimized with respect to the NDRI (Los et al., 2005). Direct inversion of PRI can be achieved by substituting equation 5 into the general form of the NDRI, yielding (angular dependencies of the kernels are not stated):

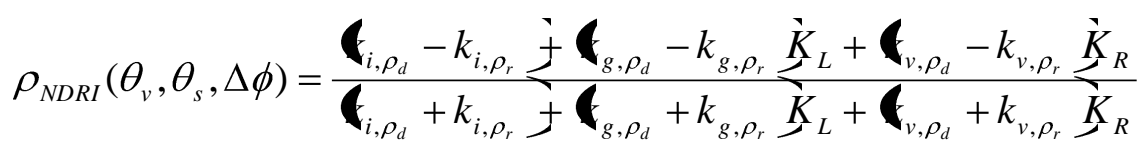

where $k_{\rho_{d}}$ and $k_{\rho_{r}}$ are the kernel weights of detection and reference band, respectively. Los et al. (2005) concluded that if the isotropic kernel weights for both the reference and the detection band are somewhat larger than zero (which holds for most land surfaces with the exception of open surface water), the majority of the variability observed in 
equation (6) can be attributed to variations in the numerator and not to variations in the denominator. Therefore, equation (6) can be simplified by considering the denominator constant, reducing it to

$$
\rho_{N D R I}\left(\theta_{v}, \theta_{s}, \Delta \phi\right)=k_{i}{ }^{\prime}+k_{g}{ }^{\prime} K_{L}+k_{v}{ }^{\prime} K_{R}
$$

where the primes indicate that the kernel coefficients in equation (7) are a reformulation of the kernel coefficients in equation (5) (Los et al., 2005).

\subsubsection{Classification of spectral observations and data analysis}

Assuming a homogeneous stand structure, the BRDF of the PRI observed by AMSPEC is a function of three key factors: 1) the view-sun geometry, 2) the prevailing sky conditions at the time data was sampled and 3) the physiological status of the vegetation canopy observed (i.e. ع). Since modeling of the reflectance distribution using

(7), assumes 2) and 3) to be constant, all PRI measurements were stratified on a half hourly basis into subsets of homogeneous environmental conditions with respect to both sky conditions and $\varepsilon$ and a separate BRDF was fitted to each strata. First, reflectance measurements were grouped into classes of observations made under approximately homogeneous sky conditions, as determined by the ratio of direct to diffuse sky radiation $(\mathrm{Q})$. These classes are hereafter referred to as $Q_{0}$ to $Q_{9}$, where $Q_{0}$ contains all spectra derived under sky conditions with $Q_{0} \in[0 . .0 .5], Q_{1} \in[0.5 . .1 .5], \ldots, Q_{8} \in[7.5 . .8 .5]$, $Q_{9} \in[>8.5]$. Second, each of these classes was then further stratified into groups of 
measurements observed under homogenous values of $\varepsilon$ as determined from flux tower instrumentation (named $\varepsilon_{0.1}$ to $\varepsilon_{3.5}$ where $\varepsilon_{0.1} \in[0 . .0 .2], \varepsilon_{0.3} \in[0.2 . .0 .4], \ldots, \varepsilon_{3.5} \in[3.4 .3 .6]$ )

The model described in (7) was fitted separately for the observations contained in each class using a robust linear least squares algorithm (bi-square-weighted iterations) (Holland and Welsch 1997, DuMouchel and O'Brien 1989). Using $k_{i}{ }^{\prime}, k_{g}{ }^{\prime}$ and $k_{v}{ }^{\prime}$, all PRI observations within each class were normalized to a constant view and illumination geometry (June $21^{\text {st }}$ solar noon, looking north at a vertical zenith angle of $62^{\circ}$ ) to separate physiologically induced changes in PRI from those caused by other effects and permit the examination of changes in canopy NDRI strictly as a function of towermeasured ع. A subsequent analysis investigated the relationship between the BRDF scattering components and different physiological and atmospheric states as determined by $\varepsilon$ and the ratio of direct to diffuse downwelling radiation, respectively. All BRDF kernel components can, under certain conditions, be related to tower-measured $\varepsilon$ (Hall et al., 2007). The impact of the volumetric NDRI kernel component, however, is smaller for wavelengths with similar optical properties in stacked canopies and consequently, a focus was set on isotropic and geometric kernel weights. The isotropic kernel weight, representing Lambertian reflectance (Roujean et al., 1992, Wanner et al., 1995), was hypothesized to change as a function of $\varepsilon$ as xanthophyll related pigment changes are closely related to PRI (Gamon et al., 1992, Peñuelas et al. 1995, Sims et al. 2005). Geometric BRDF scattering, representing crown shape and hence shading effects between tree crowns, was hypothesized to change as a function of the atmospheric conditions observed, as shading effects will be more distinct with 
increasingly clear sky conditions. Also, under clear conditions, the geometric component was expected to be correlated to $\varepsilon$ across the different strata.

\section{Results}

\subsection{Modeling the BRDF}

Stratification of the flux tower observations of sky conditions and $\varepsilon$ resulted in 31 unique physiological and atmospheric states identified for the one-year study period. Figure 2 shows an overview of the classes derived and number of observations made in each class (total number of observations: 246,276 ).

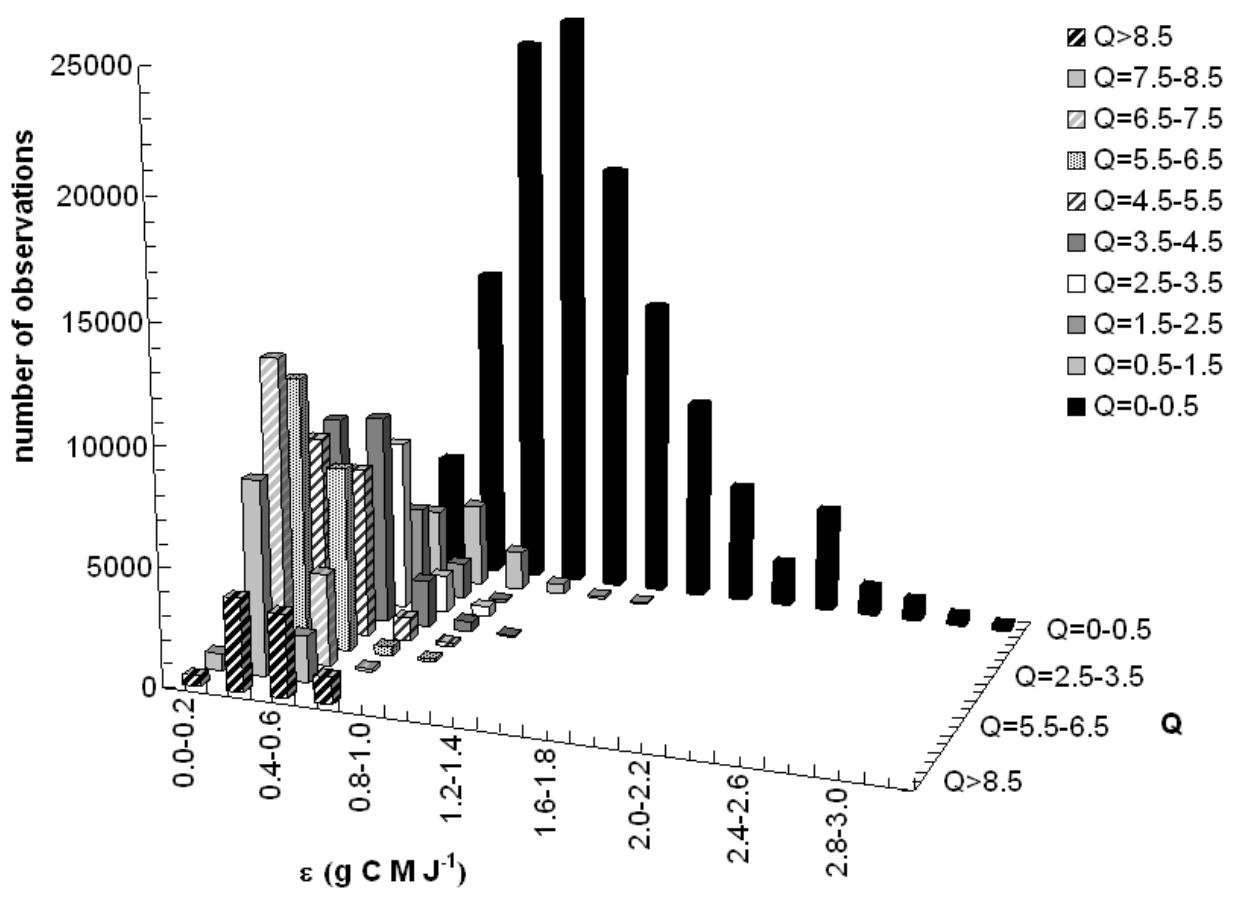

Figure 2: Number of observations made for classes of homogeneous sky conditions (ratio of direct to diffuse radiation, Q) and homogenous physiological states $(\varepsilon)$. A total of 31 classes were derived with observations in it, $n_{\text {total }}=246,276$. The class width for $\varepsilon$ is $0.2 \mathrm{~g} \mathrm{C} \mathrm{MJ}^{-1}$, the class width for $Q$ is 1 . 
Variations in $\varepsilon$ were largest under diffuse radiation conditions, with values ranging from 0 to $3.6 \mathrm{~g} \mathrm{C} \mathrm{MJ}^{-1}$, and $\varepsilon$ was generally lower under clear sky conditions. Directional reflectance effects were smallest under overcast situations and increasing with increasingly clear skies. The BDRF models fitted separately for each class of observations were, on average, able to explain of $60 \%$ of variations in PRI (mean $\left.\bar{r}^{2}=0.6, \sigma=0.2, \mathrm{p}<0.05\right)$ with the most significant results being achieved for clear sky observations. An overview of the amount of spectral variation explained under different sky conditions is given in Figure 3 .

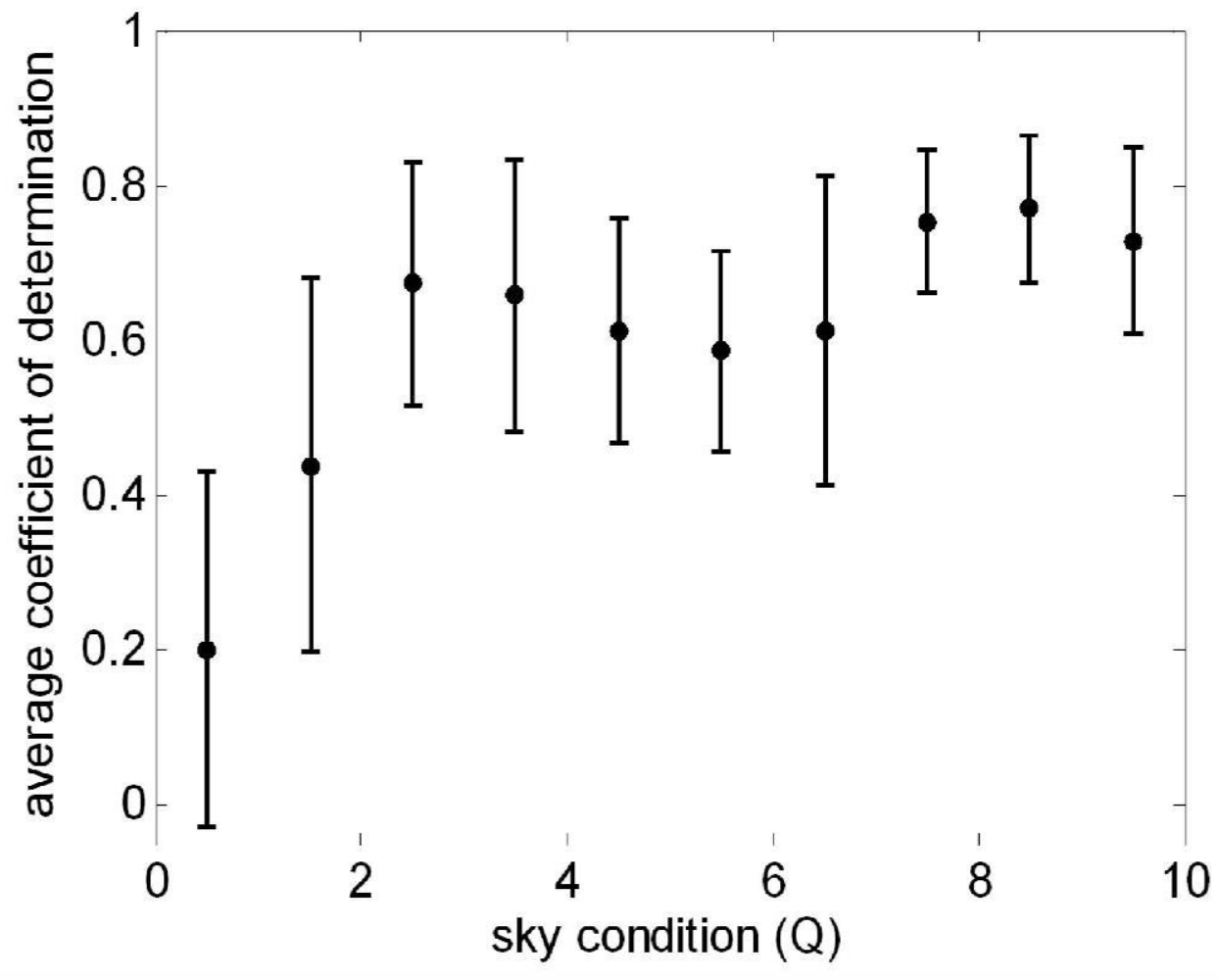

Figure 3: Average coefficient of determination for fitting the BRDF functions to observations made under different cloud conditions $\left(Q_{1}-Q_{9}\right)$. The amount of variation explained by the BRDF increases with increasingly clear skies as directional reflectance effects under diffuse radiation conditions are minimal. The errorbars represent the deviation from the mean according to different classes of $\varepsilon$. No relations were found between the quality of BRDF fitting and different levels of $\varepsilon$. 
BRDF surfaces modeled for different $Q$ and $\varepsilon$ strata are shown in Figure 4A-J. Each graph (5A-J) represents a different range of sky conditions ( $Q_{0}$ to $\left.Q_{9}\right)$, from cases where almost all radiation is scattered, diffuse light (Figure $4 \mathrm{~A}$ ) to observations acquired under completely clear skies (Figure 4J). The different BRDF surfaces shown within each figure are the PRI surfaces for all $\varepsilon$ strata, while sky conditions remain constant. The $\mathrm{PRI}$ values are plotted for each $(\mathrm{x}, \mathrm{y})$ location beneath the tower as defined by Cartesian coordinate system whose origin is the tower, and whose positive $Y$ axis is aligned with geodetic north (to the right in 5A-J). All reflectance surfaces shown are standardized to a constant sun geometry (June $21^{\text {st }}$, solar noon). The variability of PRI due to $\varepsilon$ is most apparent under cloudy sky conditions $(5 \mathrm{~A})$, showing the full range of $\varepsilon$ values from 0-3.6 $\mathrm{g} \mathrm{C} \mathrm{MJ}^{-1}$. Raw measured PRI values varied between -0.2 and 0 , the BRDF corrected, normalized surface reflectance of PRI ranged between -0.1 and 0 , respectively. 
A

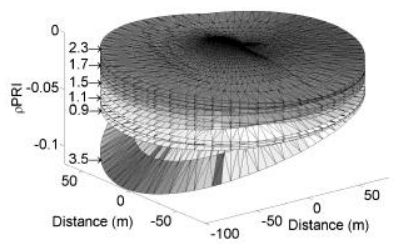

D

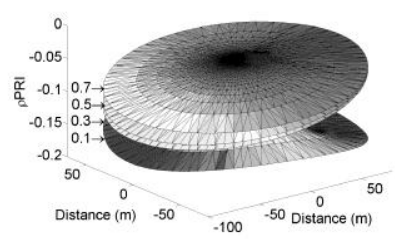

G
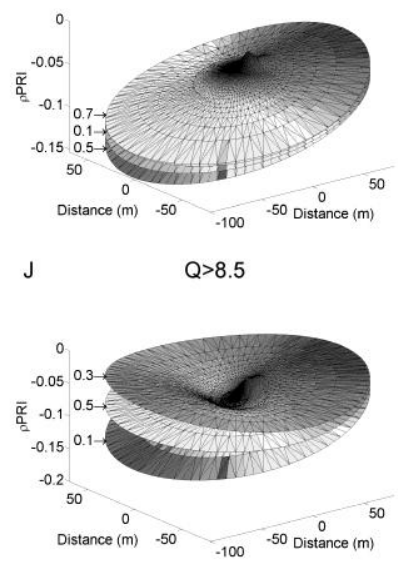

B

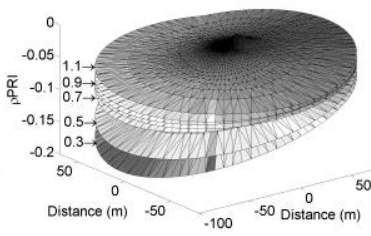

E

$Q=3.5-4.5$

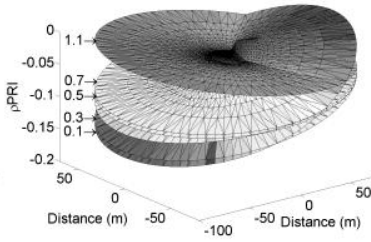

$\mathrm{H}$

$Q=6.5-7.5$
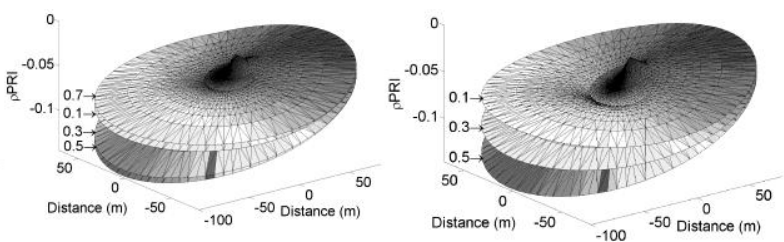

$Q=1.5-2.5$

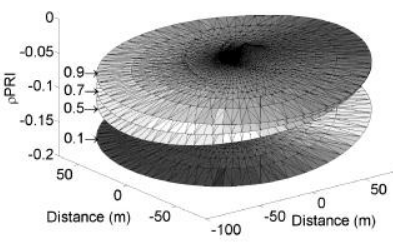

$\mathrm{F}$

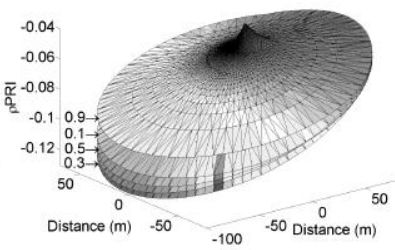

I

$\mathrm{Q}=7.5-8.5$

Distance (m) $\quad-50 \quad-100-50$ Distance (m)

Figure 4A-J: BRDF surfaces obtained for homogeneous sky and physiological condition. Each figure represents one state of cloudiness from overcast (A) to perfectly clear skies (J). The different BRDF surfaces within each figure represent different physiological states $(\varepsilon)$ while the sky conditions for observations within each figure are constant. Low $\varepsilon$ values result in low PRI measurements, while higher $\varepsilon$ measurements result in PRI values up to 0 . All BRDF surfaces are standardized to a common viewing geometry (June $21^{\text {st }}, 2006$, solar noon). The colors of the surfaces are used to emphasize the topographic properties of the surfaces. The labels within the figures represent the $\varepsilon$ strata for each BRDF surface. The width in $\varepsilon$ strata is 0.2 , that is, a surface labelled " 0.3 " for instance, represents reflectance observations made under conditions where $\varepsilon$ values were between 0.2 and 0.4 . 
The difference between sunlit ( min) and shaded ( max) PRI ( $\triangle \mathrm{PRI})$ within each strata shown in Figure 4 (=tilt of each BRDF surface) is depending on both directional reflectance effects (because of the amount of shadow cast seen by the observing probe) and $\varepsilon$ induced changes in leaf level reflectance (because sunlit parts of the canopy are more likely to be exposed to excess light levels, causing a conversion of violaxanthin to zeaxanthin and resulting in a lowering of PRI) (Hall et al., 2007). As a result, $\triangle \mathrm{PRI}$ is highest under clear skies and high stress levels (low $\varepsilon$ ) (Figure 5) and decreases with decreasing $Q$ and increasing $\varepsilon$ values.

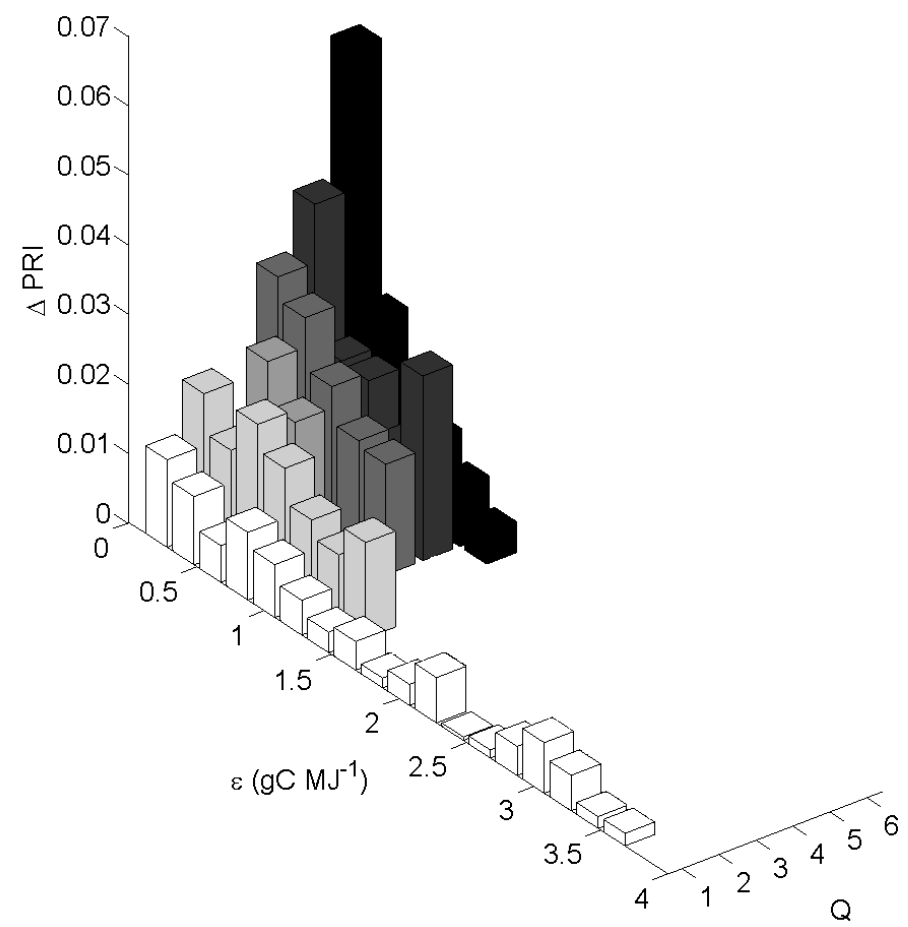

Figure 5: Difference between maximum (south) and minimum (north) PRI ( $\triangle \mathrm{PRI}$ ) for different $\varepsilon$ and $Q$ strata for the directionally corrected case (zenith angle of $62^{\circ}$ ). Higher stress levels (low $\varepsilon$ ) cause differences between sunlit and shaded parts of the canopy to be more distinct. Also $\triangle P R I$ is increasing with increasingly clear skies. 


\subsection{Analysis of BRDF scattering}

Figure 6 shows the relationship between $\varepsilon$ and the isotropic kernel weight as given in Figure 4 for observations made under different sky conditions $\left(Q_{0}-Q_{9}\right)$. The datapoints in each figure show the value of the isotropic BRDF scattering component fitted as a function of $\varepsilon$ using weighted least squares, the error-bars give the standard error of the BRDF estimate. Significant correlations were found between $\varepsilon$ and the isotropic kernel weights $\left(\bar{r}^{2}=0.62, \sigma=0.28, \mathrm{p}<0.05\right)$ for all sky conditions $\left(Q_{0}-Q_{9}\right)$. 

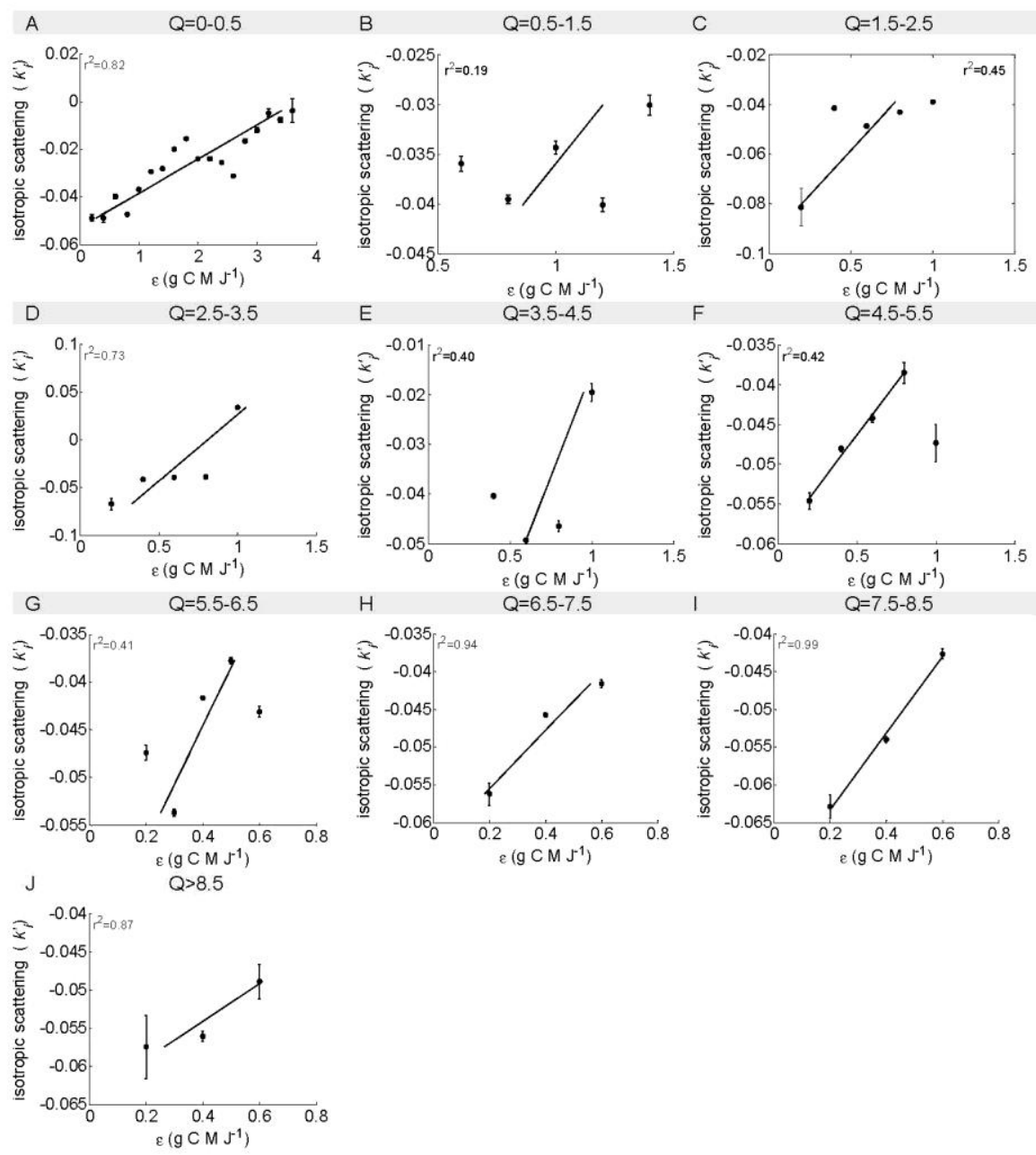

Figure 6A-J: Relationship between isotropic PRI scattering and $\varepsilon$ for different sky conditions state of cloudiness from overcast (A) to perfectly clear skies (J) (corresponding to Figure 4). Each figure represents one state of cloudiness, the datapoints show the isotropic BRDF scattering components derived for different classes of $\varepsilon$ (corresponding to the surfaces in each Figure 3). 
Figure 7 shows the relationship between $Q$ and the geometric scattering component for different levels of $\varepsilon$. Data with $\varepsilon>0.8 \mathrm{~g} \mathrm{C} \mathrm{MJ}^{-1}$ were excluded from this analysis as these data show no observations for clear sky conditions (Figure 4). Significant relationships were found between $Q$ and the geometric scattering components for all observed classes of $\varepsilon\left(\varepsilon_{0.1}\left(r^{2}=0.5\right), \varepsilon_{0.3}\left(r^{2}=0.8\right), \varepsilon_{0.5}\left(r^{2}=0.7\right)\right.$ and $\left.\varepsilon_{0.7}\left(r^{2}=0.7\right)(\mathrm{p}<0.05)\right)$.

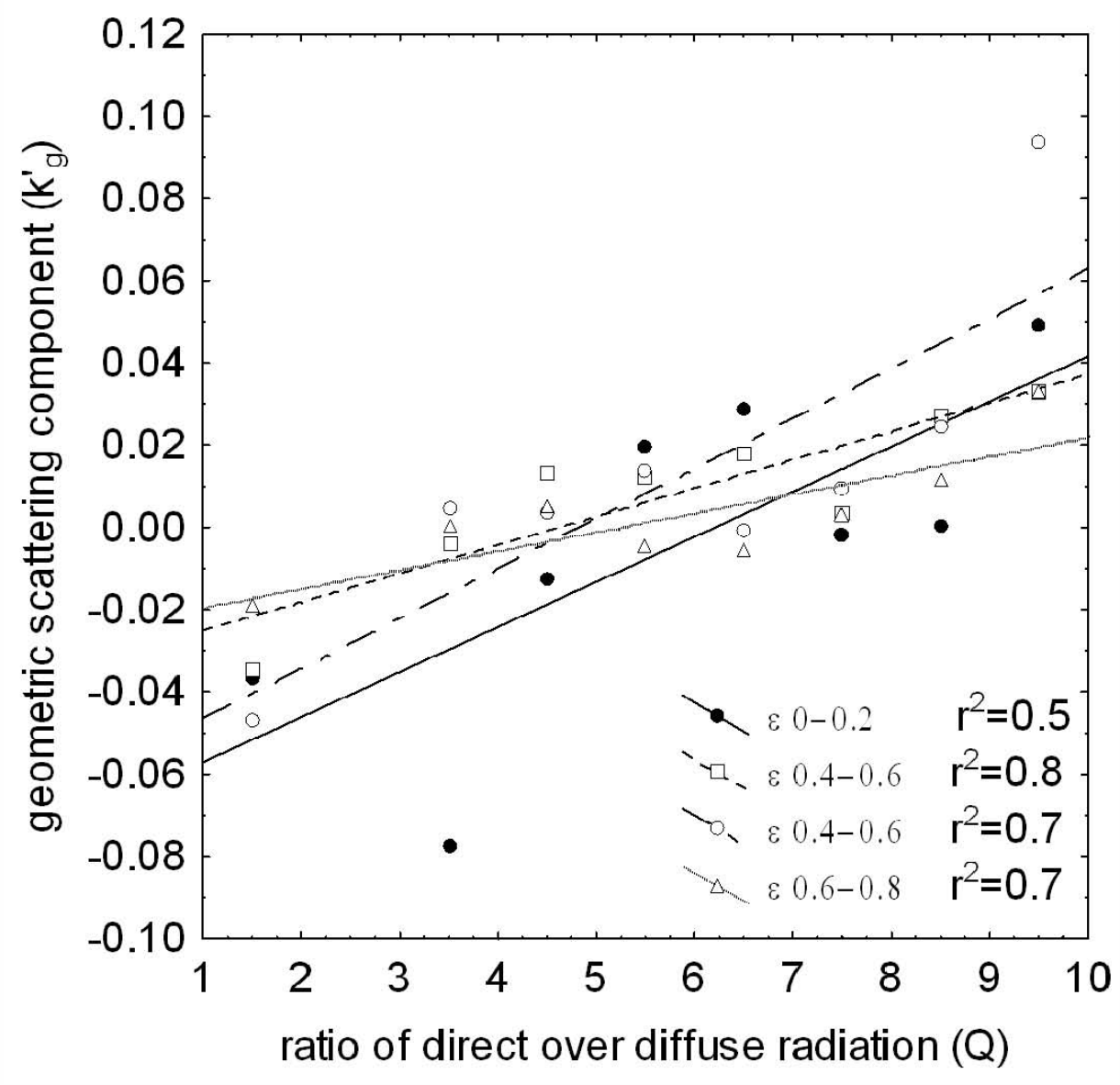

Figure 7: Relationship between geometric PRI scattering and state of cloudiness (Q) for $\varepsilon_{0.1}, \varepsilon_{0.3}, \varepsilon_{0.5}$ and $\varepsilon_{0.7}$. Higher classes of $\varepsilon$ had no observations for clear sky conditions and were hence excluded from the analysis. The relationship is significant for all examined cases $(p<0.05)$. 


\subsection{Using BRDF modeling to determine canopy level $\varepsilon$}

Figure 8A-B shows the relationship between $\varepsilon$ and $\mathrm{PRI}$ for the directionally uncorrected (8A) and directionally corrected case (8B). The directional effects on uncorrected PRI measurements are visible in Figure $8 \mathrm{~A}$, showing large variability of PRI compared to half hourly flux based estimates of $\varepsilon$. As a result, only moderate relations exist between canopy level PRI and $\varepsilon\left(r^{2}=0.37, \mathrm{p}<0.05\right)$. As shown in Figure $8 \mathrm{~B}$, the standardization of PRI to a common view- and solar illumination geometry (June $21^{\text {st }}$ solar noon)) significantly enhances the PRI- $\varepsilon$ relationship to $r^{2}=0.82(\mathrm{p}<0.05)$ as the vertical range of PRI values for a given $\varepsilon$ is largely reduced.

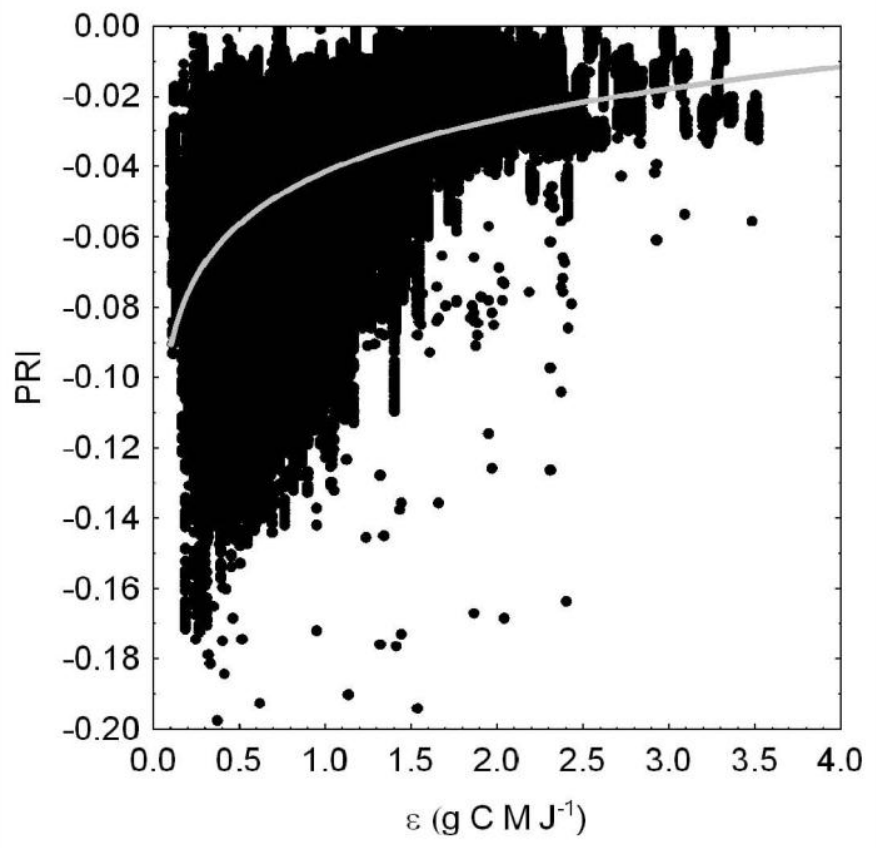

Figure 8A: Relationship between measured PRI and $\varepsilon$ for all observations made between April $1^{\text {st }} 2006$ and March $31^{\text {st }}$ 2007. The large variability in PRI is due to directional reflectance effects $\left(r^{2}=0.37, p<0.05\right)$. 


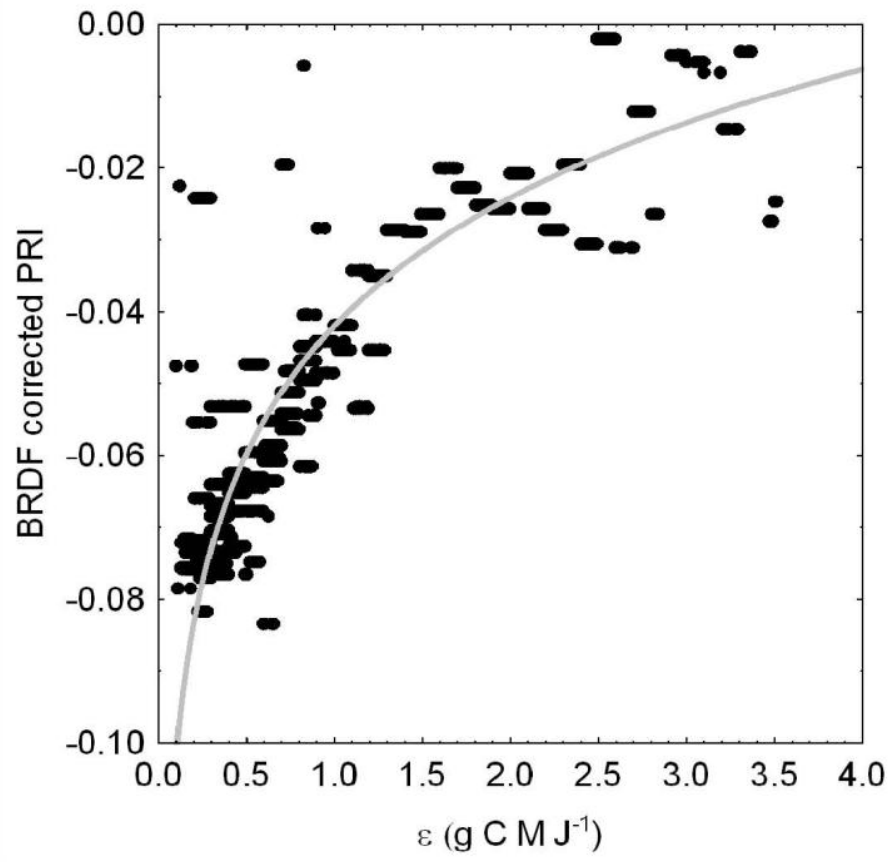

Figure 8B: Relationship between directionally corrected PRI and $\varepsilon$ for the vegetation period of 2006. The variability in PRI due to directional reflectance effects is largely reduced and the relationship between PRI and $\varepsilon$ is significantly increased $\left(r^{2}=0.82, p<0.05\right)$. Due to normalization of different view and sun angles, multiple points show identical values and are placed above each other. The absolute number of observations is not reduced with respect to Figure $8 \mathrm{~A}$.

Figure 9 demonstrates the ability of the directionally standardized canopy level PRI to track changes in $\varepsilon$ over half hourly (Figure 9A) and daily (Figure 9B) time steps. The upper line shows half hourly and daily estimates of $\varepsilon$, respectively between April $1^{\text {st }}$ 2006 and March $31^{\text {st }} 2007$, while the lower line shows the corresponding directionally corrected PRI measurements of this time period. Figure $9 \mathrm{~A}$ represents the same data as Figure 8, Figure 9B represents the data aggregated over diurnal cycles. The directionally corrected PRI closely follows the pattern of $\varepsilon$ as determined from EC flux measurements over half hourly and daily time steps, thereby underlining the potential of directionally corrected canopy PRI to permanently track $\varepsilon$ on a stand level. The figure 
also reveals the large amount of variability in stand level $\varepsilon$ over the course of one year, with moderate patterns apparent due to seasonality or other regularities (i.e. $\varepsilon$ is highest in early summer while it decreases during the dry period in late August and is also generally lower during the winter months).

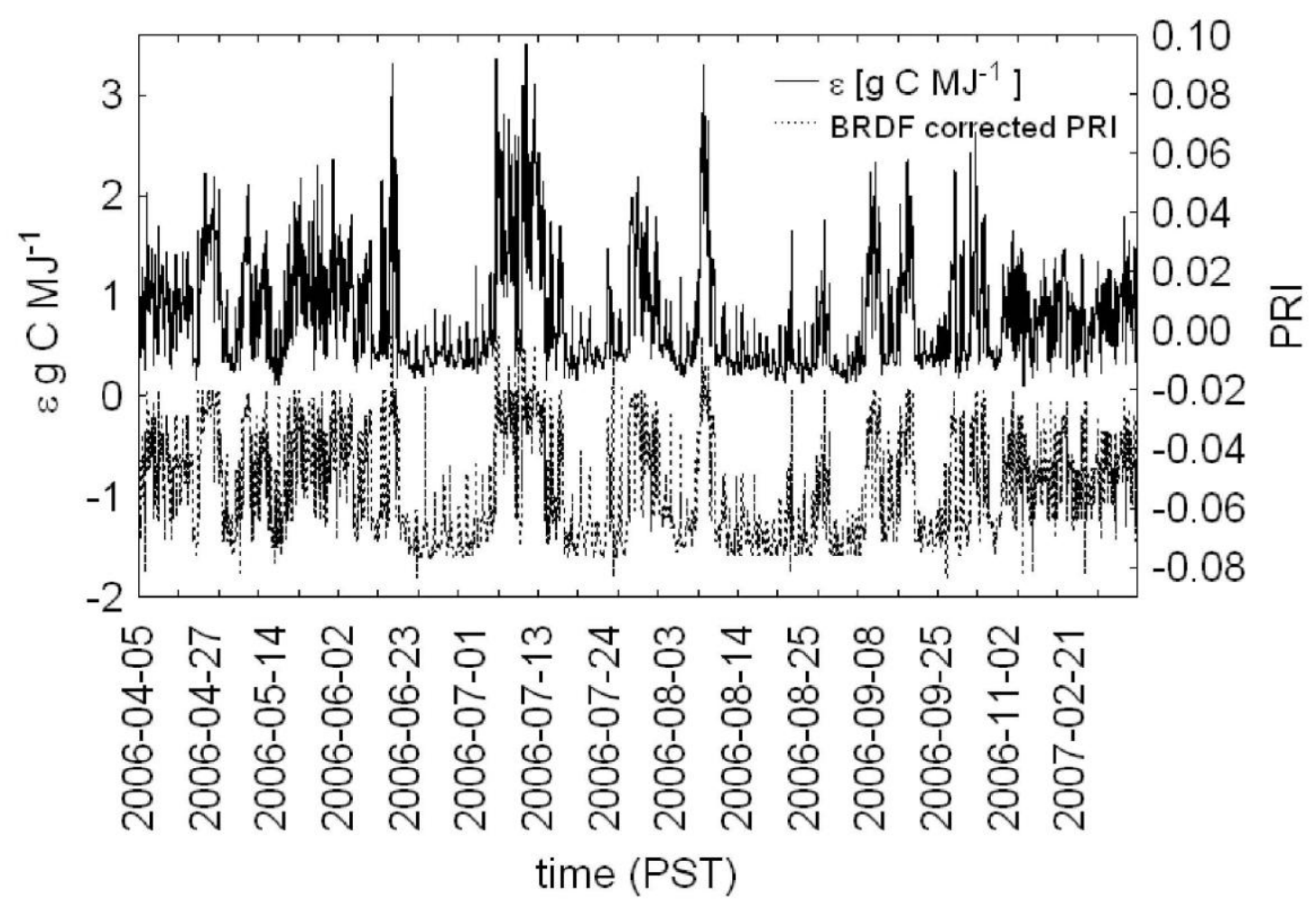

Figure 9: Temporal variability of half hourly $\varepsilon$ as determined from eddy flux measurements between April $1^{\text {st }}$ 2006 and March $31^{\text {st }} 2007$ over half hourly (A) and daily (B) time steps. Values ranged between 0 and $3.6 \mathrm{~g} \mathrm{C}$ $\mathrm{M} \mathrm{J}^{-1}$. Changes in canopy level $\varepsilon$ can be tracked using a directionally corrected PRI, following its pattern closely. 


\section{Discussion and Conclusions}

This study introduced an approach for predicting $\varepsilon$ on the stand scale using high frequency multi-angular spectral reflectance measurements obtained from an automated, tower-based radiometer platform. A simple classification technique, clustering homogeneous atmospheric and physiological conditions, with separate semiempirical kernel driven BRDF models being computed for each of these classes, successfully separated directional reflectance effects existing in year round multiangular PRI measurements from physiologically induced changes in canopy reflectance

related to $\varepsilon$ (Figure 4, Figure 8 ). Hall et al. (2007) demonstrated conclusively that the $531 \mathrm{~nm}$ signal associated with reductions in canopy $\varepsilon$ was clearly detectable at stand scales and under a wide range of view and illumination conditions. The results of this study confirm these findings using high frequency year round observations thereby demonstrating the capacity of the PRI signal to track changes in $\varepsilon$ over diurnal and seasonal cycles in a Douglas fir forest (Figure 9).

The differences shown between the BRDF surfaces (Figure 4,6) lead us to conclude that changes in the PRI signal seen by the instrument under homogeneous illumination conditions (see Figure 4a as an example) are mostly explained by changes in leaf level reflectance. For instance, isotropic scattering was significantly related to changes in $\varepsilon$ (Figure 6), which emphasizes its representativeness of bulk leaf reflectance in the tree crown. While the relationship between $\varepsilon$ and isotropic scattering was significant $(p<0.05)$ for all states of cloudiness, the restricted variability of $\varepsilon$ under very clear sky conditions 
$(Q>6.5)$ yielded limited numbers of BRDF surfaces and, as a result, the coefficients of determination between cloudy and sunny data are not directly comparable.

This study also shows that changes in canopy level $\varepsilon$ are related to both leaf level reflectance changes and directional changes in canopy reflectance (Figure 5) as sunlit regions of the canopy are more likely to be exposed to excess light levels than shaded parts. This result is consistent with previous studies (e.g. Demmig Adams et al., 1996) and was also demonstrated by Hall et al. (2007). The dependency of the geometric scattering component on $Q$ can be explained by the dependency of this component on shadow fractions, which become more distinct with increasingly clear skies. This result is consistent with Hall et al. (2007) finding that PRI can only depend on shadow fraction when the reflectance of the $531 \mathrm{~nm}$ band differs between the shaded and sunlit portions of the canopy. The selected modeling approach facilitates comparison of continuous spectral observations to half hourly estimates of $\varepsilon$ obtained using the eddy covariance technique (Figure 8b). The result is notably enhanced compared to the directionally uncorrected case $(8 \mathrm{~A})$. The strong correlation was found between $\varepsilon$ and directionally corrected PRI (Figure 8) is persistent throughout the year and can be used to accurately track $\varepsilon$ over half hourly and daily time steps (Figure 9a and b). While the seasonal patterns were not very distinct, highest values for $\varepsilon$ were found in early summer with the canopy undergoing only moderate stress levels, while photosynthetic efficiency was reduced during late August and early September, presumably due to drought conditions found at the site, and also during the winter months. 
While the approach introduced in this paper accounts for changes plant physiology related to $\varepsilon$, Barton and North (2001) showed that PRI reflectance may also dependent on other, longer term physiological processes influencing the pigment pool size (=carotenoid to chlorophyll ratio). The assumption that this variable is approximately constant over the study period can be justified for the evergreen forest by the favourable nutrient conditions found at the site and the distinct temperate climate allowing tree growth year round. Pigment pool size may, however, be a restriction to other, more variable sites or broad leaf forests. Another assumption made in here is that the stand is uniform and no differences in canopy reflectance occurred due to differences in structure or species.

An important conclusion of this study is that multiple look angles are helpful for minimizing stand geometric effects, thereby enhancing the clarity of the physiological signal observed. The methodology shown in this study can be easily extended to investigate similar relationships in other forest types, but can possibly also be adapted for multi-angle satellite observations, which, when normalized to a common view- and illumination geometry and under cloud-free conditions, will allow geosynchronous satellites to monitor diurnal changes in $\varepsilon$ by correcting for extraneous effects from a changing sun elevation throughout the day, and for varying view angles with latitude and longitude. A possible way to achieve this is by calibrating BRDF observations to canopies with higher levels of $\varepsilon$ first (which can be measured for instance ground based instrumentation), and comparing these data to observations of more stressed canopies in the afternoon. 
Permanently established canopy reflectance measurements are vital components of ongoing research aiming at up-scaling PRI based estimates of $\varepsilon$ to landscape, regional and global scales. Airborne or satellite based observations can only provide detection of spectral features at isolated temporal snapshots determined by the satellite's or aircraft's overpass (Sims et al., 2005) and, as a result, considerable gaps exist between these observations. Instruments and methodologies like the ones developed in this study can help to fill these gaps by identifying physiological cycles of the vegetation observed and serve as calibration for the broader band spectral observations available from satellite data. Ultimately, a comprehensive understanding of correlations between variations in $\varepsilon$ and spectral reflectance in both xanthophyll and fluorescence related absorption features can help developing models suitable for determination of global productivity from space. 


\section{Acknowledgements}

We would like to thank Dominic Lessard, Rick Ketler and Andrew Sauter from UBC Faculty of Land and Food Systems (LFS) for their assistance in technical design, installation, and maintenance of the radiometer platform. Baozhang Chen (also UBC LFS) is thanked for analyzing and processing eddy flux data. This research is partially funded by a postgraduate scholarship of the German Academic Exchange Service (DAAD) to Hilker, an NSERC Discovery Grant to Coops, and funds provided to UBC from Fluxnet-Canada, NSERC and BIOCAP. 


\section{Reference List}

Asner, G. (1998). Biophysical and biochemical sources of variability in canopy reflectance. Remote Sensing of Environment 64, 225-226.

Barton CVM, North PRJ (2001). Remote sensing of canopy light use efficiency using the photochemical reflectance index: model and sensitivity analysis. Remote Sensing of Environment 78, 264-273.

Baldocchi, D.D. (2003). Assessing the Eddy Covariance Technique for Evaluating Carbon Dioxide Exchange Rates of Ecosystems: Past, Present and Future. Global Change Biology 9, 479-492.

Barnsley, M.J., Lewis, P., Sutherland, M. and Muller, J.P. (1997). Estimating Land Surface Albedo in the Hapex-Sahel Southern Super-Site: Inversion of Two Brdf Models Against Multiple Angle Asas Images. Journal of Hydrology 189, 749778.

Black, T.A., Den Hartog, G., Neumann, H.H., Blanken, P.D., Yang, P.C., Russell, C., Nesic, Z., Lee, X., Chen, S.G., Staebler, R. and Novak, M.D. (1996). Annual Cycles of Water Vapour and Carbon Dioxide Fluxes in and Above a Boreal Aspen Forest. Global Change Biology 2, 219-229.

Blanken, P.D., Black, T.A., Neumann, H.H., Den Hartog, G., Yang, P.C., Nesic, Z. and Lee, X. (2001). The Seasonal Water and Energy Exchange Above and Within a Boreal Aspen Forest. Journal of Hydrology 245, 118-136.

Chen, J. (1996). Evaluation of vegetation indices and a modified simple ratio for boreal applications. Canadian Journal of Remote Sensing 22, 229-242.

Chen, J. and Black, T. (1991). Measuring leaf area index of plant canopies with branch architecture. Agricultural and Forest Meteorology 57, 1-12.

Chen, J.M. and Leblanc, S.G. (1997). A Four-Scale Bidirectional Reflectance Model Based on Canopy Architecture. IEEETransactions on Geoscience and Remote Sensing 35, 1316-1337.

Chen, J.M., Liu, J., Leblanc, S.G., Lacaze, R. and Roujean, J.L. (2003). Multi-angular optical remote sensing for assessing vegetation structure and carbon absorption. Remote Sensing of Environment 84, 516-525.

Chen, J.M., Menges, C.H. and Leblanc, S.G. (2005). Global Mapping of Foliage Clumping Index Using Multi-Angular Satellite Data. Remote Sensing of Environment 97, 447-457.

Chen, J.M., Govind, A., Sonnentag, O., Zhang, Y.Q., Barr, A. and Amiro, B. (2006) Leaf Area Index Measurements at Fluxnet-Canada Forest Sites. Agricultural and Forest Meteorology 140, 257-268. 
Demmig-Adams, B. and Adams, W.W. (1996). The Role of Xanthophyll Cycle Carotenoids in the Protection of Photosynthesis. Trends in Plant Science 1, 2126.

Demmig-Adams, B. and Adams, W.W. (2000). Photosynthesis - Harvesting Sunlight Safely. Nature 403, 371-372

Demmig-Adams, B., Moeller, D.L., Logan, B.A. and Adams, W.W. (1998). Positive Correlation Between Levels of Retained Zeaxanthin Plus Antheraxanthin and Degree of Photoinhibition in Shade Leaves of Schefflera Arboricola (Hayata) Merrill. Planta 205, 367-374.

Drewitt, G.B., Black, T.A., Nesic, Z., Humphreys, E.R., Jork, E.M., Swanson, R., Ethier, G.J., Griffis, T. and Morgenstern, K. (2002). Measuring Forest Floor Co2 Fluxes in a Douglas-Fir Forest. Agricultural and Forest Meteorology 110, 299-317.

Drolet, G.G., Huemmrich, K.F., Hall, F.G., Middleton, E.M., Black, T.A., Barr, A.G. and Margolis, H.A. (2005). A Modis-Derived Photochemical Reflectance Index to Detect Inter-Annual Variations in the Photosynthetic Light-Use Efficiency of a Boreal Deciduous Forest. Remote Sensing of Environment 98, 212-224.

DuMouchel, W.H., and F.L. O'Brien (1989). Integrating a Robust Option into a Multiple Regression Computing Environment. Computer Science and Statistics:

Proceedings of the 21st Symposium on the Interface, Alexandria, VA: American Statistical Association.

Field C. and Mooney, H.A. (1986). The photosynthesis-nitrogen relationship in wild plants. In: T.Givnish, editor. On the Economy of Plant Form and Function. Cambridge Univ. Press, Cambridge, U.K. 22-55.

Field CB (1991). Ecological scaling of carbon gain to stress and resource availability. In: Integrated Responses 27 of Plants to Stress (eds. Mooney, HA Winner, SE Pell, EJ). Academic Press, San Diego, CA. 28; 35-65.

Filella, I., Amaro, T., Araus, J.L. and Penuelas, J. (1996). Relationship Between Photosynthetic Radiation-Use Efficiency of Barley Canopies and the Photochemical Reflectance Index (PRI). Physiologia Plantarum 96, 211-216.

Gamon, J.A. and Surfus, J.S. (1999). Assessing Leaf Pigment Content and Activity With a Reflectometer. New Phytologist 143, 105-117.

Gamon, J.A., Field, C.B., Bilger, W., Bjorkman, O., Fredeen, A.L. and Peñuelas, J. (1990). Remote-Sensing of the Xanthophyll Cycle and Chlorophyll Fluorescence in Sunflower Leaves and Canopies. Oecologia 85, 1-7.

Gamon, J.A., Peñuelas, J. and Field, C.B. (1992). A Narrow-Waveband Spectral Index That Tracks Diurnal Changes in Photosynthetic Efficiency. Remote Sensing of Environment 41, 35-44. 
Gamon JA, Filella I, Peñuelas J (1993). The dynamic 531-nanometer? reflectance signal: a survey of twenty angiosperm species. Yamamoto HY, Smith CM (Eds). Photosynthetic Responses to the Environment. American Society of Plant Physiologists, Rockville. pp. 172-177.

Gao, F., Schaaf, C.B., Strahler, A.H., Jin, Y. and Li, X. (2003). Detecting Vegetation Structure Using a Kernel-Based Brdf Model. Remote Sensing of Environment 86, 198-205.

Goel, N.S. and Grier, T. (1988). Estimation of Canopy Parameters for Inhomogeneous Vegetation Canopies From Reflectance Data .3. Trim - a Model for RadiativeTransfer in Heterogeneous 3-Dimensional Canopies. Remote Sensing of Environment 25, 255-293.

Goetz, S.J., Prince, S.D., Goward, S.N., Thawley, M.M., Small, J. and Johnston, A. (1999). Mapping Net Primary Production and Related Biophysical Variables With Remote Sensing: Application to the Boreas Region. Journal of Geophysical Research-Atmospheres 104, 27719-27734.

Goodwin G Regeneration Study on the logged-off lands of the Comox Logging and Railway Company Oyster River Forest Survey No R 72 Survey file No 0124780 BC Forest Service 39p and Map

Goulden, M.L. and Crill, P.M. (1997). Automated Measurements of Co2 Exchange at the Moss Surface of a Black Spruce Forest. Tree Physiology 17, 537-542.

Hall, F.G., Townshend, J.R. and Engman, E.T. (1995). Status of Remote-Sensing Algorithms for Estimation of Land-Surface State Parameters. Remote Sensing of Environment 51, 138-156.

Hall, F.G., Huemmrich, K.F., Goetz, S.J, Sellers, P.J., Nickeson, J.E. (1992). Satellite Remote-Sensing of Surface-Energy Balance-Success, Failures and Unresolved Issues in FIFE. Journal of Geophysical Research-Atmospheres 97, 1906119089.

Hall, F.G., Hilker, T., Coops, N.C., Lyapustin, A., Huemmrich, K.F., Middleton, E.M., Drolet, G.G., Margolis, H.A., Black, T.A. (2007). Can Light-Saturated Reductions in Canopy Photosynthetic Capacity Be Observed From Space? Remote Sensing of Environment , submitted

Hilker, T., Coops, N.C., Nesic, Z., Wulder, M.A. and Black, T.A. (2007). Instrumentation and approach for unattended year round tower based measurements of spectral reflectance . Computers and Electronics in Agriculture 56, 72-84.

Holland, P.W., and R.E. Welsch (1977).Robust Regression Using Iteratively Reweighted Least-Squares. Communications in Statistics: Theory and Methods, A6, 813-827. 
Humphreys, E.R., Black, T.A., Morgenstern, K., Cai, T.B., Drewitt, G.B., Nesic, Z. and Trofymow, J.A. (2006). Carbon Dioxide Fluxes in Coastal Douglas-Fir Stands at Different Stages of Development After Clearcut Harvesting. Agricultural and Forest Meteorology 140, 6-22.

Jassal, R.S., Black, T.A., Cai, T.B., Morgenstern, K., Li, Z., Gaumont-Guay, D. and Nesic, Z. (2007). Components of Ecosystem Respiration and an Estimate of Net Primary Productivity of an Intermediate-Aged Douglas-Fir Stand. Agricultural and Forest Meteorology 144, 44-57.

Jupp, D.L.B. (1998). Directional Radiance and Emissivity Measurement Models for Remote Sensing of the Surface Energy Balance. Environmental Modelling \& Software 13, 341-351.

Justice, C.O., Vermote, E., Townshend, J.R.G., Defries, R., Roy, D.P., Hall, D.K., Salomonson, V.V., Privette, J.L., Riggs, G., Strahler, A., Lucht, W., Myneni, R.B., Knyazikhin, Y., Running, S.W., Nemani, R.R., Wan, Z.M., Huete, A.R., Van Leeuwen, W., Wolfe, R.E., Giglio, L., Muller, J.P., Lewis, P. and Barnsley, M.J. (1998). The Moderate Resolution Imaging Spectroradiometer (Modis): Land Remote Sensing for Global Change Research. IEEE Transactions on Geoscience and Remote Sensing 36, 1228-1249.

Kljun, N., Kastner-Klein, P., Fedorovich, E. and Rotach, M.W. (2004). Evaluation of Lagrangian Footprint Model Using Data From Wind Tunnel Convective Boundary Layer. Agricultural and Forest Meteorology 127, 189-201.

Leclerc, M.Y. and Thurtell, G.W. (1990). Footprint Prediction of Scalar Fluxes Using a Markovian Analysis. Boundary-Layer Meteorology 52, 247-258.

Leuning, R., Hughes, D., Daniel, P., Coops, N.C. and Newnham, G. (2006). A MultiAngle Spectrometer for Automatic Measurement of Plant Canopy Reflectance Spectra. Remote Sensing of Environment 103, 236-245.

Li, X.W. and Strahler, A.H. (1986). Geometric-Optical Bidirectional Reflectance Modeling of a Conifer Forest Canopy. IEEE Transactions on Geoscience and Remote Sensing 24, 906-919.

Liu, J., Chen, J.M., Cihlar, J. and Chen, W. (2002). Net Primary Productivity Mapped for Canada at 1-Km Resolution. Global Ecology and Biogeography 11, 115-129.

Los, S.O., North, P.R.J., Grey, W.M.F. and Barnsley, M.J. (2005). A Method to Convert AVHRR Normalized Difference Vegetation Index Time Series to a Standard Viewing and Illumination Geometry. Remote Sensing of Environment 99, 400411.

Lucht, W., Schaaf, C.B. and Strahler, A.H. (2000). An Algorithm for the Retrieval of Albedo From Space Using Semiempirical Brdf Models. IEEE Transactions on Geoscience and Remote Sensing 38, 977-998. 
Margolis, H.A., Flanagan, L.B. and Amiro, B.D. (2006). The Fluxnet-Canada Research Network: Influence of Climate and Disturbance on Carbon Cycling in Forests and Peatlands. Agricultural and Forest Meteorology 140, 1-5.

Monteith, J.L. (1972). Solar-Radiation and Productivity in Tropical Ecosystems. Journal of Applied Ecology 9, 747-766.

Monteith, J.L. (1977). Climate and Efficiency of Crop Production in Britain. Philosophical Transactions of the Royal Society of London Series B-Biological Sciences 281, 277-294.

Morgenstern, K., Black, T.A., Humphreys, E.R., Griffis, T.J., Drewitt, G.B., Cai, T.B., Nesic, Z., Spittlehouse, D.L. and Livingstone, N.J. (2004). Sensitivity and Uncertainty of the Carbon Balance of a Pacific Northwest Douglas-Fir Forest During an El Nino La Nina Cycle. Agricultural and Forest Meteorology 123, 201219.

Myneni, R.B., Hoffman, S., Knyazikhin, Y., Privette, J.L., Glassy, J., Tian, Y., Wang, Y., Song, X., Zhang, Y., Smith, G.R., Lotsch, A., Friedl, M., Morisette, J.T., Votava, P., Nemani, R.R. and Running, S.W. (2002). Global Products of Vegetation Leaf Area and Fraction Absorbed Par From Year One of Modis Data. Remote Sensing of Environment 83, 214-231.

Nichol, C.J., Huemmrich, K.F., Black, T.A., Jarvis, P.G., Walthall, C.L., Grace, J. and Hall, F.G. (2000). Remote Sensing of Photosynthetic-Light-Use Efficiency of Boreal Forest. Agricultural and Forest Meteorology 101, 131-142.

Nichol, C.J., Lloyd, J., Shibistova, O., Arneth, A., Roser, C., Knohl, A., Matsubara, S. and Grace, J. (2002). Remote Sensing of Photosynthetic-Light-Use Efficiency of a Siberian Boreal Forest. Tellus Series B-Chemical and Physical Meteorology 54, 677-687.

Peñuelas, J., Filella, I. and Gamon, J.A. (1995). Assessment of Photosynthetic Radiation-Use Efficiency With Spectral Reflectance. New Phytologist 131, 291296.

Peñuelas, J., Gamon, J.A., Fredeen, A.L., Merino, J. and Field, C.B. (1994). Reflectance Indexes Associated With Physiological-Changes in Nitrogen-Limited and Water-Limited Sunflower Leaves. Remote Sensing of Environment 48, 135146.

Peñuelas, J., Llusia, J., Pinol, J. and Filella, I. (1997). Photochemical Reflectance Index and Leaf Photosynthetic Radiation-Use-Efficiency Assessment in Mediterranean Trees. International Journal of Remote Sensing 18, 2863-2868.

Peñuelas, J., Munne-Bosch, S., Llusia, J. and Filella, I. (2004). Leaf Reflectance and Photo- and Antioxidant Protection in Field-Grown Summer-Stressed Phillyrea 
Angustifolia. Optical Signals of Oxidative Stress? New Phytologist 162, 115124.

Prince, S. and Goward, S. (1995). Global primary production: a remote sensing approach. Journal of Biogeography 22, 815-835.

Privette, J.L., Myneni, R.B., Tucker, C.J. and Emery, W.J. (1994). Invertibility of a 1-D Discrete Ordinates Canopy Reflectance Model. Remote Sensing of Environment 48, 89-105.

Reda, I. and Andreas, A. (2004). Solar Position Algorithm for Solar Radiation Applications. Solar Energy 76, 577-589.

Roujean, J.L., Leroy, M. and Deschamps, P.Y. (1992). A Bidirectional Reflectance Model of the Earths Surface for the Correction of Remote-Sensing Data. Journal of Geophysical Research-Atmospheres 97, 20455-20468.

Ross, J.K. (1981). The Radiation Regime and Architecture of Plant Stands, 392pp., Dr. W.JunkPublishers, The Hague

Schmid, H.P. and Lloyd, C.R. (1999). Spatial Representativeness and the Location Bias of Flux Footprints Over Inhomogeneous Areas. Agricultural and Forest Meteorology 93, 195-209.

Sims, D.A., Rahman, A.F., Cordova, V.D., Baldocchi, D.D., Flanagan, L.B., Goldstein, A.H., Hollinger, D.Y., Misson, L., Monson, R.K., Schmid, H.P., Wofsy, S.C. and $\mathrm{Xu}$, L.K. (2005). Midday Values of Gross Co2 Flux and Light Use Efficiency During Satellite Overpasses Can Be Used to Directly Estimate Eight-Day Mean Flux. Agricultural and Forest Meteorology 131, 1-12.

Strahler, A.H. and Jupp, D.L.B. (1990). Modeling Bidirectional Reflectance of Forests and Woodlands Using Boolean Models and Geometric Optics. Remote Sensing of Environment 34, 153-166.

Strugnell, N.C. and Lucht, W. (2001). An Algorithm to Infer Continental-Scale Albedo From AVHRR Data, Land Cover Class, and Field Observations of Typical BRDFs. Journal of Climate 14, 1360-1376.

Turner, D.P., Urbanski, S., Bremer, D., Wofsy, S.C., Meyers, T., Gower, S.T. and Gregory, M. (2003). A Cross-Biome Comparison of Daily Light Use Efficiency for Gross Primary Production. Global Change Biology 9, 383-395.

Wang, Z., Zeng, X., Barlage, M., Dickinson, R.E., Gao, F. and Schaaf, C.B. (2004). Using Modis Brdf and Albedo Data to Evaluate Global Model Land Surface Albedo. Journal of Hydrometeorology 5, 3-14. 
Wanner, W., Li, X. and Strahler, A.H. (1995). On the Derivation of Kernels for KernelDriven Models of Bidirectional Reflectance. Journal of Geophysical ResearchAtmospheres 100, 21077-21089.

Xiao, X.M., Zhang, Q.Y., Braswell, B., Urbanski, S., Boles, S., Wofsy, S., Berrien, M. and Ojima, D. (2004). Modeling Gross Primary Production of Temperate Deciduous Broadleaf Forest Using Satellite Images and Climate Data. Remote Sensing of Environment 91, 256-270. 